\title{
A DIMENSÃO MORAL DOS DIREITOS DE AUTOR NO CONTEXTO DA SOCIEDADE COMPLEXA
}

\author{
Alejandro Knaesel Arrabal ${ }^{1}$ \\ Feliciano Alcides Dias ${ }^{2}$
}

\begin{abstract}
RESUMO: Este artigo propõe uma releitura das prerrogativas morais do autor previstas no direito brasileiro, tendo em vista o caráter complexo da sociedade contemporânea. Desenvolvido a partir de revisão bibliográfica, o estudo aborda o conceito de sociedade como sistema complexo, bem como procura demostrar que, a partir desta matriz conceitual, a concepção de moral no campo dos direitos autorais não comporta mais a uma legitimidade demiúrgica concebida a partir da individualidade. $\mathrm{Na}$ esteira do projeto de liberdade iluminista, refratário às forças heterônomas disciplinares, a moral moderna distanciou-se da crença nos valores universais, conferindo força ao arbítrio subjetivo. Os direitos morais de autor, caracterizados como prerrogativas de personalidade, são fruto destes pressupostos. No contexto da sociedade complexa, a relação entre autor e obra escapa aos fundamentos da moral que se confunde com individualidade volitiva, pretensamente descolada das injunções do meio no qual o processo criativo se manifesta.
\end{abstract}

Palavras-Chave: Sociedade Complexa; Autor; Individualidade; Autonomia; Moral.

\section{THE MORAL DIMENSION OF COPYRIGHT IN THE CONTEXT OF COMPLEX SOCIETY}

\begin{abstract}
This article proposes a re-reading of the moral author's prerogatives foreseen in brazilian law, considering the complex nature of contemporary society. Developed from a bibliographical review, the study approaches the concept of society as a complex system, as well as seeks to demonstrate that, from this conceptual matrix, the conception of moral in the field of copyright no longer has a demiurgical legitimacy conceived from the individuality. In the wake of the enlightenment freedom project, refractory to disciplinary heteronomous forces, modern morality has distanced itself from the belief in universal values, giving strength to subjective agency. The author's moral rights, characterized as prerogatives of personality, are the fruit of these presuppositions. In the context of complex society, the relation between author and work escapes the foundations of morality that is confused with volitional individuality, allegedly detached from the injunctions of the environment in which the creative process is manifested.
\end{abstract}

Keywords: Complex Society; Author; Individuality; Autonomy; Moral.

\footnotetext{
${ }^{1}$ Doutor em Direito Público pela Universidade do Vale dos Sinos - UNISINOS. Mestre em Ciências Jurídicas pela Universidade do Vale do Itajaí - UNIVALI. Especialista em Direito Administrativo pela Universidade Regional de Blumenau - FURB. Professor de Metodologia da Pesquisa em Cursos de Especialização da FURB. Professor de Direito da Propriedade Intelectual e Metodologia da Pesquisa Jurídica do Curso de Graduação em Direito da FURB. Professor de Direito Administrativo do Curso de Graduação em Direito do Centro Universitário de Brusque - UNIFEBE. Membro dos grupos de pesquisa Constitucionalismo, Cooperação e Internacionalização - CONSTINTER (CNPq-FURB) e Estado, Sociedade e Relações Jurídicas Contemporâneas (CNPq-FURB). Membro do NIT - Núcleo de Inovação Tecnológica da FURB. E-mail: arrabal@ furb.br

${ }^{2}$ Doutor em Direito Público pela Universidade do Vale dos Sinos - UNISINOS. Mestre em Ciências Jurídicas e Especialista em Direito Civil pela Universidade do Vale do Itajaí - UNIVALI. Professor Titular de Direito Civil e Direito Processual Civil da Universidade Regional de Blumenau - FURB. Professor e Coordenador da Escola de Magistratura do Estado de Santa Catarina - ESMESC. Pesquisador na linha "Acesso à Justiça, Gestão de Conflitos e Organizações" vinculada ao Grupo de Pesquisa "Direitos Fundamentais, Cidadania \& Justiça" certificado pela FURB junto ao CNPq. Advogado. Árbitro. E-mail: feliciano@ furb.br
} 


\section{INTRODUÇÃO}

O fenômeno autoral é consagrado na ordem jurídica como fato jurídico que dispensa qualquer formalidade constitutiva. Autor é "pessoa física criadora" (BRASIL, Lei $n^{\circ}$ 9610/1998, art. 11) e a "criação", na qualidade de evento existencialmente irrefutável, confere ao seu agente (autor) o domínio e os benefícios presentes e futuros em razão do objeto criado (obra). Embora a exclusividade sobre as prerrogativas patrimoniais seja temporária, a dimensão moral é admitida como permanente.

Assim, a vinculação nominativa, a integridade da obra e a reputação do agente são aspectos que qualificam a dimensão moral dos direitos autorais, facilmente reconhecidos como monolíticos e inerentes ao arbítrio do autor. Contudo, a sociedade contemporânea demanda novas leituras a respeito da vida produtiva e das relações interpessoais, com especial atenção aos fatores que legitimam ou cerceiam o acesso à cultura.

Nesta linha, o presente artigo propõe uma releitura das prerrogativas morais do autor previstas no direito brasileiro, tendo em vista o caráter complexo da sociedade contemporânea. A ideia de moral, para o direito autoralista, demanda ressignificação. A perspectiva corrente no assunto insiste em qualificar o autor como entidade germinal, pautada em uma concepção de autossuficiência e determinismo volitivo, o que não se coaduna com o caráter social da expressão criativa.

Por opção metodológica, o estudo foi desenvolvido a partir de revisão bibliográfica e encontra-se estruturado em duas partes. A primeira aborda o conceito de sociedade como sistema complexo, tendo como tônica a influência da teoria sistêmica, em sua matriz relacional. A segunda demonstra, a partir desta matriz conceitual, que a concepção de moral no campo dos direitos autorais não comporta mais a legitimidade demiúrgica concebida a partir da individualidade.

$\mathrm{Na}$ esteira do projeto de liberdade iluminista, refratário às forças heterônomas disciplinares, a moral moderna distanciou-se da crença nos valores universais, conferindo força ao arbítrio subjetivo. Morin e Kern (1995, p. 81) consideram que a modernidade comportou “em seu seio a emancipação individual, a secularização geral dos valores, a diferenciação do verdadeiro, do belo, do bem".

Os direitos morais de autor, caracterizados como prerrogativas de personalidade, são fruto destes pressupostos. No contexto da sociedade complexa, a relação entre autor e obra 
escapa aos fundamentos da moral que se confunde com individualidade volitiva, pretensamente descolada das injunções do meio no qual o processo criativo se manifesta.

\section{A SOCIEDADE COMO SISTEMA COMPLEXO}

Considerações a respeito da categoria "sociedade" não escapam a noções sobre totalidade, parte, identidade e diferença, do mesmo modo que o seu conceito é facilmente tomado a partir das ideias de conjunto, corpo, organismo ou sistema. Abstrata e conceitualmente considerados, o "todo" e a "parte" assumem sentidos distintos quando confrontados. Significa dizer, inicialmente, que as partes constitutivas de um conjunto não correspondem ao todo, do mesmo modo que a totalidade não corresponde a cada uma de suas partes. Contudo, especialmente a partir da noção de conjuntos, pode-se afirmar distintamente que o todo é formado a partir da identidade de um ou mais atributos das partes.

Neste sentido, o conceito de sociedade caminha para a ideia de um conjunto de indivíduos com atributos comuns. Esta é a concepção que orienta, por exemplo, os processos de classificação adotados na biologia, ao sitiar a fauna e a flora em categorias hierárquicas como reino, filo, classe, família, gênero e espécie. (CAMPBELL, 2010). De certo modo, é também o que a ordem jurídica retrata quanto estabelece que "todos são iguais perante a lei” (BRASIL, Constituição Federal, 1988, art. 5º. Lei, portanto, reconhecida como fator de identidade relativo a cada cidadão, já que "todo o poder [inclusive o de legislar] emana do povo" (BRASIL, Constituição Federal, 1988, art. $1^{\circ}$, parágrafo único).

A relação todo/parte também pode ser observada a partir da ótica mecânico/funcionalista. Nesta linha, cada parte é dotada de atributos que, integrados funcionalmente às demais, propiciam a operabilidade do todo. Esta abordagem difere da lógica de conjuntos, na medida que o caráter funcionalista considera que a totalidade demanda partes distintas funcionalmente, mas que atuam de modo integrado a partir de suas diferenças. $\mathrm{O}$ pensamento moderno primitivo levou a sério esta leitura ao produzir ciência. Trata-se do ideal mecanicista de cariz newtoniano. Os fenômenos da existência podem ser explicados sob a premissa de causas e efeitos e suas dinâmicas assemelham-se ao funcionamento de máquinas.

Uma variação desta abordagem corresponde a ótica orgânico/funcionalista que considera a sociedade, não como um sistema mecânico no qual predomina a lógica da causalidade, mas como um sistema orgânico, cujas dinâmicas de relacionamento das partes levam em conta processos semelhantes aos que orientam os organismos vivos. No último 
século, uma vasta corrente sociológica pretendeu "ver na sociedade um análogo do organismo animal, procurando minuciosamente a equivalência entre vida biológica e vida social." (MORIN, 2011, p. 28) Neste contexto, o biólogo austríaco Ludwig von Bertalanffy (1969) propôs uma Teoria Geral dos Sistemas, para a qual entende-se por sistema:

[...] um complexo de elementos em interação. Interação significa que os elementos, $\langle\mathrm{p}\rangle$, estabelecem relações, $\langle\mathrm{R}\rangle$, de modo que o comportamento de um elemento $\langle\mathrm{p}\rangle$ em $\langle\mathrm{R}\rangle$ é diferente de seu comportamento em outra relação, $\langle\mathrm{R} 1>$. Se os comportamentos em $\langle\mathrm{R}\rangle \mathrm{e}<\mathrm{R} 1>$ não são diferentes, não há interação, e os elementos se comportam independentemente com relação às relações $\langle\mathrm{R}\rangle \mathrm{e}\langle\mathrm{R} 1\rangle$. (BERTALANFFY, 1969, p. 55-56, sem grifo no original)

Uma das importantes contribuições desta teoria foi colocar em destaque o aspecto relacional (interativo) das partes de um todo, o que permitiu gradualmente desconstruir noções newtonianas rígidas, deslocando a observação, antes focada nos atributos funcionais das partes “em si”, para as relações e seu potencial transformador para as partes e o todo.

Morin (2011, p. 20) destaca três qualidades da teoria sistêmica:

a) ter posto no centro da teoria [...] uma unidade complexa, um 'todo' que não se reduz à 'soma' de suas partes constitutivas; b) não ter concebido a noção de sistema como uma noção 'real' [no sentido de objeto, coisa], nem como uma noção puramente formal, mas como uma noção ambígua ou fantástica; c) situar-se a um nível transdisciplinar, que permite ao mesmo tempo conceber a unidade da ciência e a diferenciação das ciências [...]

A Teoria dos Sistemas desdobrou-se ao longo do século XX e, integrada à outras matrizes epistêmicas, ofereceu condições para reconhecer a sociedade como um Sistema Complexo.

Importa sempre alertar que complexidade não se confunde, a priori, com a ideia de dificuldade ou problema. A noção de complexidade passa, necessariamente, pela possibilidade de desconstruir o que ambicionou vigorosamente a ciência moderna: revelar uma realidade universal pronta, pressupostamente sonegada ao homem. Esta postura epistêmica, levada a efeito, impossibilita compreender a relação da humanidade com-e-no mundo, bem como do indivíduo com-e-na sociedade. A ideia de uma realidade a ser desvendada, antes, sonega ao homem a possibilidade de reconhecer-se em inter-ação-constituição com o que produz simbólica e materialmente. É reconhecer que toda pessoa que transforma e produz, ao transformar e produzir, simultaneamente é transformado e produzido. Freire (1989) observa que o ímpeto criativo nasce do caráter inconcluso do homem, do mesmo modo que a liberdade é possível por sua indeterminação biológica (GALIMBERTI, 2006). Neste sentido, o mundo 
não é uma instância conclusa à humanidade, assim como a humanidade não está conclusa para o mundo.

A tradição científica racional crê na especificidade dos fenômenos, nos atributos dos objetos (materiais ou imateriais) como qualidades intrínsecas dos mesmos, de modo que o observador pode ser metodologicamente neutralizado do processo de reconhecimento do que já está dado. Esta abordagem, embora limitada, não é de todo equívoca. Ignorá-la é desprezar todos os avanços científicos já conquistados pela humanidade. Ocorre que ela não basta para lidar com a realidade social contemporânea, especialmente quando a observação da vida ainda testemunha extraordinárias desigualdades e injustiças. Morin (2011, p. 13) considera que "a incapacidade de conceber a complexidade da realidade antropossocial, em sua microdimensão (o ser individual) e em sua macrodimensão (o conjunto da humanidade planetária), conduz a infinitas tragédias e nos conduz à tragédia suprema.”.

Sem prejuízo dos demais aspectos que a categoria complexidade aponta, por "sociedade complexa" considera-se aqui uma totalidade que não se traduz no agregado de constituintes, seja em relação as suas identidades, ou mesmo em razão do papel (função) que cada um assume em relação ao todo. A sociedade complexa foge a leitura do pensamento analítico porque não resulta da mera soma de suas partes. Sociedade como sistema implica na interação de múltiplos sujeitos, os quais se constituem (individualizam e identificam) em múltiplas relações. Disto resulta que a complexidade social pressupõe paradoxalmente pluralidade e unidade, diferença e identidade, bem como liberdade e limite. O caráter complexo aqui em destaque aponta para uma leitura distinta do tradicional dualismo sujeito/objeto.

A dualidade do objeto e do sujeito se coloca em termos de disjunção, de repulsão, de anulação recíproca. $O$ encontro entre sujeito e objeto anula sempre um dos dois termos: ou bem o sujeito torna-se 'ruido' (perturbação), ausência de sentido, ou bem é o objeto, poderíamos dizer o mundo, que se torna 'ruido': que importa o mundo 'objetivo' para quem entende o imperativo categórico da lei moral (Kant), para quem vive o tremor existencial da angústia e da busca (Kierkegaard). (MORIN, 2011, p. 40)

Contrário à esta concepção redutora, a complexidade informa que não há objeto sem sujeito e não há sujeito sem objeto. Com efeito, nas sociedades contemporâneas, não há como confundir o sujeito com o indivíduo. A psicanálise tem contribuído com esse aspecto, no sentido de afirmar que o "sujeito não é a consciência do Ego, muito menos o reconhecimento de um Simesmo social (Self). Ele é, ao contrário, desprendimento da imagem do indivíduo criada pelos papéis, pelas normas, pelos valores da ordem social”. (TOURAINE, 1998, p. 308). 
Associa-se esse distanciamento pelo confronto entre a liberdade pessoal do sujeito com as demandas sociais emergentes, repressão e a ordem de poder previamente estabelecida, na satisfação de seus próprios desejos.

Disto resulta que a sociedade complexa compreende uma diversidade que não pode render-se a um atomismo desmesurado, sob pena de entrar em colapso. Neste contexto, a categoria "sujeito" distingue-se da noção de "indivíduo". Na ideia de individualidade, uma pessoa se basta por si mesma, percebe-se como unidade última, indivisa, conclusa e, por consequência, fundamento legítimo do seu próprio agir e pensar.

De modo reflexo, esta leitura é herdeira da tradição metafísica que propugnava por universais, tendo em vista ancorar a existência em algum plano genuinamente estável. Para a modernidade, o indivíduo - indiviso - foi projetado como unidade monolítica que pensa logo existe (DESCARTES, 1996). Deste modo, a autonomia é justificada e percebida como independência. No mesmo sentido, a liberdade é reconhecida como ampla e irrestrita possibilidade para realização do querer. O limite, nesta leitura, não integra o conceito de liberdade. Por sua vez, a categoria "sujeito" traduz um paradoxo necessário típico da complexidade. Sujeito é quem participa ativamente da realidade em que vive (sujeito de) e, ao mesmo tempo, encontra-se imerso e sujeito a injunção desta mesma realidade.

Referir a sociedade como sistema complexo pressupõe reconhecer esta condição que distingue e une, a mesmo tempo, a parte e o todo, a unidade e o coletivo, sem disjungir. A experiência de si implica na relação com o(s) outro(s) e a vida do(s) outro(s) pressupõe a experiência de cada um. Apropriar-se é encontrar-se apropriado e, ao mesmo tempo, reconhecer a dimensão coletiva como apropriação de si.

Diante de tais situações, a sociedade deve se esmerar em construir uma nova ordem, uma transformação no arranjo da convivência humana e nas condições sociais sob as quais está assentada a política-vida.

\section{A DIMENSÃO MORAL DA AUTORIA NA SOCIEDADE COMPLEXA}

A tradição jurídica nacional conferiu direitos aos autores de obras literárias, artísticas e científicas sob dupla dimensão: uma de ordem patrimonial e outra moral. Em sentido amplo, o assunto encontra previsão normativa em sede Constitucional (BRASIL, 1988, art. $5^{\circ}$, IV, V, IX e XXVII), bem como em legislação específica (BRASIL, Lei no 9610/1998 e Lei no 9609/1998). 
Observa-se que o direito brasileiro seguiu a vertente francesa, cujo foco de proteção é "a pessoa do autor, ao contrário do sistema do copyright anglo-saxão, cuja proteção recai, principalmente, sobre a obra intelectual" (CARBONI, 2008, p. 57). Neste contexto, é reconhecida a exclusividade sobre o uso, fruição e disposição da obra, direito este transferível por contrato e transmissível aos herdeiros pelo tempo fixado em lei. A par deste domínio patrimonial e imiscuído a ele, encontra-se o domínio moral que aponta para uma espécie de vínculo indelével e de ingerência entre autor e obra, entre criador e criatura.

Em 1886, a Convenção de Berna disciplinou a matéria, asseverando que: "independentemente dos direitos patrimoniais de autor, e mesmo depois da cessão dos citados direitos, o autor conserva o direito de reivindicar a paternidade da obra e de se opor a toda deformação, mutilação ou a qualquer dano à mesma obra, prejudiciais à sua honra ou à sua reputação.” (BRASIL, Decreto no 75.699/1975 - Art. 6 bis da Convenção). Em 1948, a Declaração Universal dos Direitos Humanos reiterou o assunto ao determinar que "todo ser humano tem direito à proteção dos interesses morais e materiais decorrentes de qualquer produção científica literária ou artística da qual seja autor." (ONU, 1948 - Art. XXVII, 2 da Declaração)

O reconhecimento de uma causalidade legítima é, por certo, o ponto a partir do qual a ideia de autoria encontra lugar e produz seus efeitos. Para o senso comum autoralista, a causa da obra é o autor. Credita-se a ele o poder de plasmá-la a partir de sua visão de mundo, dos seus valores, bem como das escolhas que promove no processo de criação. O indivíduo criativo é a personalidade emancipada do ideário humanista, aquele que "libertou-se" da condição de instrumento de uma vontade superior e passou a conduzir sua vida de modo autônomo. $\mathrm{O}$ ato criativo encontra fundamento em si, a exemplo do seu feitor, como produto de uma vontade própria que não é determinada, a priori, por qualquer ordem transcendente e universal. Neste sentido, a autoria é um conceito resultante da trajetória de transformação da ideia de moralidade, do que foi outrora e do que agora representa a tônica de legitimidade do comportamento humano.

O que se conhece no campo dos "direitos de autor" tem por certa a noção de "moral" como algo relacionado a personalidade singular de um indivíduo. Assim, direitos morais são aqueles que prestigiam a liberdade e autonomia na qualidade de direitos fundamentais, a luz dos estamentos modernos.

A moral fundada na subjetividade demiúrgica, leitura esta que abriu espaço para consagração do indivíduo proprietário do que cria, é parcialmente distinta da moral que imperou 
na tradição grega e cristã. O caráter metafísico encontra-se ainda presente porquanto a obra é reconhecida como expressão do espírito humano, expressa por qualquer meio e fixa em qualquer suporte (BRASIL, Lei n ${ }^{\circ}$ 9610/1998, art. $7^{\circ}$ ).

Neste sentido, o pensamento atual alinha-se com o dualismo platônico que confere legitimidade existencial ao mundo das ideias, em detrimento do mundo físico. Difere, contudo, em relação ao reconhecimento da instância genuína da verdade e da beleza que, para o pensamento grego e cristão era transcendente e heterônoma (o Cosmos / a Natureza / o Deus vivo), enquanto para a modernidade é imanente e autônoma (a soberania da vontade autônoma). $\mathrm{O}$ autor, aquele que se autodetermina e se manifesta a partir de um cogito que lhe confirma a própria existência, é uma categoria que não encontra reconhecimento no primado clássico da moral, ancorada em valores universais.

Portanto, é possível considerar que os direitos morais autorais de cariz individualista são produtos da modernidade. Desde as sociedades primitivas, as relações de poder e sujeição eram manifestas não apenas pela força bruta, mas também, por meio da linguagem. Sustenta Echeverría (2003, p. 21) que a vida se manifesta na linguagem porque é precisamente através dela que se atribui sentido a existência. Cassirer (2011, p. 65) observa que:

Nos relatos da Criação de quase todas as grandes religiões culturais, a Palavra aparece sempre unida ao mais alto Deus criador, quer se apresente como instrumento utilizado por ele, quer diretamente como fundamento primário de onde ele próprio, assim como toda a existência e toda a ordem de existência provêm.

Krokoscz (2015, p. 58-59) lembra que "os termos carregam em si um significado que é compartilhado por um grupo idiomático, mas também cada palavra adquire sentidos variados a depender das situações e contextos nos quais é inserida. [...] às palavras são reféns dos acontecimentos históricos que as permeiam". Neste sentido, para os gregos, logos era, ao mesmo tempo, palavra (signo) e razão, determinada pela própria ordem cósmica. Logos designava a lógica do universo, bem como os signos (palavras faladas ou escritas - o verbo) que as revelavam. O sentido, portanto, não era produto do arbítrio humano ou da razão.

A verdade era dada por uma ordem pré-existente, a qual deveria ser contemplada e mimetizada. Com o predomínio da oralidade, o dizer e o fazer eram sincretizados. As narrativas (mitos) sobre "valentia" e "sabedoria" vinculavam estes e outros atributos as ações dos heróis e deuses. A teologia cristã medieval herdou a inspiração sincrética dos gregos de modo a unir a linguagem ao divino. A palavra pertencia a Deus, era o próprio Deus. O emprego da palavra pelo homem, por assim dizer, só poderia operar por préstimo divino, já que “[...] servir-se dela 
para especular mentalmente ou materialmente era quase usurpação sacrílega" (RUGIU, 1998, p. 30). Foucault (2001, p. 274-275) lembra que:

O discurso, em nossa cultura (e, sem dúvida, em muitas outras), não era originalmente um produto, uma coisa, um bem; era essencialmente um ato um ato que estava colocado no campo bipolar do sagrado e do profano, do lícito e do ilícito, do religioso e do blasfemo. Ele foi historicamente um gesto carregado de riscos antes de ser um bem extraído de um circuito de propriedades.

O uso da palavra e, mais especialmente, a atribuição de nomes, determinava a autoridade. Ao dominante era conferido o poder de nominar e, por consequência, evocar, apontar e imputar responsabilidades e prerrogativas ao dominado. $\mathrm{O}$ batismo consagra o domínio de Deus sobre os indivíduos a partir do nome. Em Isaías (capítulo 43, versículo 1) evocar o nome implica em um gesto de apropriação: "não temas, porque eu te remi; chamei-te pelo teu nome, tu és meu".

De agrupamentos de pessoas à delimitação de terras, inúmeras instâncias de domínio eram formalmente instituídas a partir da vinculação a nomes. Por certo, existiram na antiguidade interditos relacionados a falsa atribuição ou referencialidade nominativa, mas em razão de fatores distintos das bases que orientam a legitimidade moderna dos direitos morais de autor. No mundo antigo, a "paternidade nominativa" que indicava a origem das obras literárias, artísticas e científicas de modo geral, prestava-se muito mais para consagrar moralmente arquétipos de valores universais vinculados a identidades de grupos, do que efetivamente prestigiar interesses de indivíduos, em razão de suas singularidades. Os direitos morais do autor da modernidade como prerrogativas fundadas na individualidade da pessoa, não encontram lugar no mundo antigo.

A palavra moral deriva do latim mos ou mores, que indica um modo de agir, costume ou hábito (PEREIRA, 1991, p. 20). Embora o termo tenha se desdobrado historicamente em diversos sentidos, para efeito deste estudo, destacam-se duas leituras: a moral como repertório de valores universais que determinam a conduta humana e, sob perspectiva diversa, a moral que se manifesta no campo do arbítrio, algo próximo à personalidade e às faculdades humanas que justificam a autodeterminação. A primeira leitura é fruto de uma concepção de mundo ordenado e finito, para o qual faz sentido admitir a existência de valores universais determinados pela ordem cósmica e garantidores da estabilidade social. A segunda emergiu com o homem racional iluminista, que reconhece sua posição no mundo como protagonista de sua própria existência. Todorov (2008, p. 50-53) neste sentido observa que: 
[...] da revolução realizada pelo pensamento das Luzes encontra-se um duplo movimento, negativo e positivo, de liberação com relação às normas impostas de fora e de construção das novas normas, escolhidas por nós mesmos. O bom cidadão - escreve Rousseau - é aquele que sabe "agir segunda as máximas de seu próprio julgamento". [...] Ele não só opta resolutamente pela origem humana e não divina de todo poder, mas também declara que esse poder não pode ser transmitido, somente confiado [...] Os homens são conduzidos por sua vontade e seus desejos, por suas afeições e suas consciências, e também por forças sobre as quais eles não têm nenhum domínio; não obstante, a razão pode aclará-los quando se engajam na busca do verdadeiro e do justo. (Sem grifos no original)

As obras literárias e artísticas, antes das bases que permitiram ao mundo moderno conceber o sujeito autor, não eram produto direto (e legítimo) de uma vontade individual. Desde sempre as letras e as artes foram objeto de admiração, mas o questionamento sobre quais forças determinavam suas existências, dirigia os olhares para fora dos sujeitos. Em geral, o artista não era quem genuinamente criava, ele era instrumento de uma força superior a ele. Sua ação era vista como desprovida de uma causa moral subjetiva, o poder demiúrgico encontrava-se em outro lugar. O prestígio e reputação do artista existiam, quando muito, como um desdobramento das instâncias heterônomas de poder.

O que distingue a concepção medieval de autoria, segundo Seán Burke, é o pressuposto que o discurso é, primordialmente, uma questão de caráter público ao invés de consciência privada. [...] $\mathrm{O}$ autor daquela época não estava autorizado a criar o que hoje se entende por literatura, mas apenas a expressar a voz de Deus. Nesse campo, o autor medieval aparece como um puro gesto de inscrição e não de expressão, pois não está voltado para escrever as suas próprias intensões pessoais. (CARBONI, 2010, p. 37)

Com a modernidade esta leitura muda. A criatividade como atributo pessoal afirma-se no mesmo momento que a moral é deslocada do plano heterônomo para o campo do arbítrio subjetivo. Atualmente, observa Ribeiro (1995, p. 62) “a ideia de um eu individual está incorporada ao senso comum, fazendo parte da cultura, e do sistema de valores contemporâneos. Considera-se que [...] todo indivíduo é dotado de autonomia para dirigir suas ações". Contudo, "não existe moral pura, isolada pelo indivíduo, sem o seu aspecto de concordância entre indivíduos, a comunidade e a herança que ela traz como história, sociedade, natureza e cultura.” (PEREIRA, 1991, p. 22).

Para Elias (1994, p. 17) "há uma clara ligação entre os abismos que se abrem entre indivíduo e sociedade, ora aqui, ora ali, em nossas estruturas de pensamento, e as contradições entre exigências sociais e necessidades individuais que são um traço permanente de nossa vida”. Bauman (2008, p. 69) aduz que “a individualização traz, uma liberdade sem precedentes para 
experimentar - mas também traz uma tarefa sem precedentes de lidar com suas consequências". No atual cenário, a figura do autor tende a reconhecer-se como a autoridade sobre o que produz.

A palavra 'autor' deriva do latim auctor, que, por sua vez, deriva, através de uma cadeia linguística, de uma palavra que significa aumentar ou desenvolver. Auctor significa alguém que dá origem ou promove [...]. Autoridade e autor têm a mesma raiz e as práticas medievais davam-lhes um sentido idêntico. Os autores, em sentido medieval, são aqueles cujos textos têm autoridade, os que podem ser comentados, mas não contraditos. (MOURÃO, 2001)

Importante observar que a identidade destas categorias evidencia a sujeição, supostamente óbvia, entre a obra e o seu criador. Consagra o autor como indivíduo a quem se reconhece a condição de origem da criação intelectual, e, por consequência, a legitimidade para o exercício de direitos exclusivos sobre a criação. Esta noção centralizadora e narcísica foi colocada sob suspeita no transcurso do século XIX para o século XX, com especial participação da crítica literária, que reconheceu ao autor um papel secundário em relação ao discurso.

A obra não será, portanto, resultante de uma expressão singular. Barthes (2004, p. 62), inspirado em Nietzsche, anuncia a "morte do autor" e refere o texto como "um espaço de dimensões múltiplas, onde se casam e se contestam em escrituras variadas, das quais nenhuma é original". O autor não antecede a obra e esta não retrata o olhar e as motivações do autor. Nesta linha, Foucault (2001) considerou o autor não como sujeito, mas como atributo funcional do discurso. O autor está para a obra e não a obra para o autor. Sujeito torna-se objeto e objeto torna-se sujeito. De modo geral, para este movimento crítico literário, o esforço em atribuir autonomia ao discurso traduz o combate ao emprego do conhecimento como veículo de poder e dominação. Negar a autoria é negar uma autoridade burguesa e opressora.

A despeito destas críticas, o reconhecimento dos direitos de ordem patrimonial e moral aos autores de obras literárias, artísticas e científicas encontrou solo fértil para seu cultivo e positivação normativa. A partir de Howard, Carboni (2010, p. 85) destaca que, nos últimos três séculos, os atributos de propriedade, autonomia, originalidade e moralidade creditados ao indivíduo-autor são “considerados como dados inquestionáveis. Entretanto, o seu aparecimento na história demonstra que tais atributos são, evidentemente, arbitrariedades culturais das condições tecnológicas e econômicas da sociedade que os construiu".

Ocorre que, o modelo de desenvolvimento tecnológico e econômico predominante na trajetória de consolidação da indústria e, por consequência, da sociedade de mercado, abriu espaços para modelos emergentes sob lógicas e dinâmicas que privilegiam a difusão ampla e descentrada do conhecimento, operada por tecnologias de informação. Afirma-se no 
contemporâneo uma espécie de retorno a transcendência, mas sob distinto cariz "que se projeta a partir das individualidades diluídas na imanência da linguagem e das comunicações em rede" (ARRABAL, 2017, p. 169). Para Carboni (2009, p. 471), "as novas tecnologias possibilitam o aparecimento de um novo tipo de proposta estética, calcada na interatividade, na recombinação e na criação como ato coletivo".

Neste cenário, as prerrogativas autorais demandam ressignificação. No plano moral, o que se encontra positivado no direito brasileiro leva em conta dois vetores: o que se tornou comum chamar de "paternidade", e outro, aqui referido como "integridade lato sensu". A primeira encontra-se analiticamente disposta nos incisos I e II do artigo 24 da lei autoral (BRASIL, Lei ${ }^{\circ}$ 9.610/1998), a segunda espraia-se do inciso III ao VII.

$\mathrm{O}$ reconhecimento da paternidade corresponde ao direito de "reivindicar, a qualquer tempo, a autoria da obra" (inciso I), bem como de ter o "nome, pseudônimo ou sinal convencional indicado ou anunciado, como sendo o do autor, na utilização da obra" (inciso II). No plano da sociedade complexa, a referencialidade nominal assume importante papel no sentido de aproximar a liberdade da responsabilidade no exercício da expressão criativa. Assim, a nominação representa, ao mesmo tempo e reciprocamente, um direito e um dever moral, alinhado com o que dispõe a Constituição quando consagra a liberdade de manifestação do pensamento e, a par disto, veda o anonimato (BRASIL, Constituição Federal, 1988, art. 5º IV).

No campo da integridade lato sensu, a partir do que dispõe a legislação em comento, evidenciam-se os valores de perpetuação e de controle vinculados ao arbítrio do autor, os quais desdobram-se nos seguintes aspectos: acesso público (incisos III e VI), estabilidade material, simbólica e de imagem da obra e do autor (incisos IV, V e VII). Observa-se de imediato que estas prerrogativas apontam para uma evidente ingerência, quando não se confundem com aspectos relativos ao próprio exercício de direitos patrimoniais.

Apreçada observação destes dispositivos leva a conclusão que o exercício de direitos patrimoniais, ainda que legitimamente transferidos, permanecem subordinados ao arbítrio moral do autor. Tal leitura pode ser transformada, na medida que a dimensão moral seja operada, tendo em vista o caráter complexo da sociedade. Prerrogativas morais e patrimoniais demandam diálogo e ponderação, para fora do campo narcísico do indivíduo, sem que isto represente a anulação do sujeito autor.

A possibilidade de a obra vir a ser conhecida pela sociedade encontra seu primeiro obstáculo no direito do autor de "conservar a obra inédita” (inciso III). Do étimo latino, inédito é o que não se encontra disponível ao público (prefixo in que aponta negação, somado a palavra 
editus que indica notoriedade pública). A publicação não é necessariamente um conceito ancorado estritamente ao sentido de acesso, mas representa historicamente um fator de prestígio e poder.

O deslocamento da esfera individual para uma instância coletiva (universal) é um movimento, como já se observou neste estudo, impensável antes da modernidade. O que se tinha como habitual (moral) era justamente o contrário: a universalidade determinava a vida de cada indivíduo. Inscrever-se na esfera pública não era uma prerrogativa individual. Até certo ponto, a modernidade inovou neste sentido e, no campo dos direitos autorais, conferiu ao indivíduo a "chave" de acesso a instância pública.

Contudo, observa-se que, embora a lei tenha conferido ao autor o direito de conservar a obra inédita, e, em razão disto, permitiu a ele determinar o momento que ela alcance o plano social, a "chave" para a efetivação desta prerrogativa ainda é determinada por instâncias heterônomas. A legítima publicação de conhecimento científico, por exemplo, encontra-se sob o crivo de periódicos vinculados às instituições públicas e privadas. Também o acesso a notoriedade e a fama encontra-se sob o controle de corporações midiáticas, em que pese o massivo desenvolvimento das plataformas tecnológicas de comunicação em rede.

Ainda sobre o acesso ao público, estabelece o inciso VI do artigo 24 que o autor pode "retirar de circulação a obra ou de suspender qualquer forma de utilização já autorizada, quando a circulação ou utilização implicarem afronta à sua reputação e imagem”. Mais uma vez, tal prerrogativa, quando levada a efeito a partir da concepção tradicional de autoria (centralizadora e narcísica), tem o potencial para instaurar flagrantes injustiças. Na mesma linha, porém voltado ao sentido de preservação, o inciso IV do artigo 24 consagra como direito moral do autor o de "assegurar a integridade da obra, opondo-se a quaisquer modificações ou à prática de atos que, de qualquer forma, possam prejudicá-la ou atingi-lo, como autor, em sua reputação ou honra". Já o inciso $\mathrm{V}$ atribui ao autor o direito de "modificar a obra, antes ou depois de utilizada". Por fim, o inciso VII confere o direito de "acesso a exemplar único e raro da obra" a fim de preservar a memória do trabalho realizado.

Em que pese a norma garantir prévia indenização para terceiros frente as hipóteses dos incisos V - modificação da obra - e VI - retirada de circulação, (BRASIL, Lei no 9610/1998, art. $24, \S 3^{\circ}$ ), bem como determine que o acesso a exemplar único e raro previsto no inciso VII seja exercido de modo que "cause o menor inconveniente possível” ao detentor da obra, observa-se a prevalência da dimensão moral centrada na figura do autor. 
Para oportunizar uma interpretação adequada destes dispositivos, é preciso levar em conta que o sentido estético e/ou utilitário que uma obra oferece ao mundo cultural é algo que não se reduz ao olhar e as pretensões de seu autor. Reconhecer que os múltiplos papeis que uma obra pode alcançar socialmente seja algo determinado estritamente por seu criador, é negar a relação complexa entre indivíduo/sociedade e sociedade/indivíduo que atravessa o processo criativo.

A reputação e a imagem que a obra e o autor assumem são constructos de uma dinâmica social que não nascem exclusivamente de uma interioridade volitiva. Neste contexto, é possível ressignificar a afirmação de Sartre (1987) quando afirma que a existência precede a essência. Partindo do conceito de sociedade complexa deste estudo, a essência e a existência são aspectos da vida que se interpolam, de modo que sujeitar a obra a ingerência germinal do autor é desprezar os processos criativos que, em grande medida, manifestam-se de modo integrativo.

\section{CONCLUSÃO}

O campo moral dos direitos do autor não se confunde com uma pauta heterônoma de valores, nem mesmo se reduz a prerrogativas de um indivíduo autônomo. A personalidade do autor e a sua relação com a obra representam um envio social que pressupõe identidade e diferença, singularidade e universidade. Criar é transformar o mundo e ter consciência de que também se é transformado por ele.

Inovações no campo das Tecnologias de Informação e Comunicação incorporaram mudanças em nossa sociedade, com reflexos na vida cultural que, por consequência, repercutem na ordem jurídica autoralista. Considerando que os direitos de autor incidem nas mais diversas atividades cotidianas, especialmente de cunho criativo, faz-se necessário enfrentar o desafio de interpretar as normas vigentes em harmonia com a realidade social, ressignificando conceitos e reorganizando práticas.

A ideia que a obra representa uma emergência da autonomia do autor deve ser substituída pela ideia do autor como sujeito moral do processo criativo. Disto resulta uma visão que não despreza o relevante papel do autor, mas o coloca como efetivo partícipe e interlocutor de um mundo cultural em transformação. Promotor "em si" e "na sociedade" de um diálogo permanente que revela a reciprocidade constitutiva entre as possibilidades e os limites do processo criativo, bem como entre os direitos e as responsabilidades envolvidas. 


\section{REFERÊNCIAS}

ARRABAL, Alejandro Knaesel. Propriedade intelectual, inovação e complexidade. Rio de Janeiro: Lumen Juris, 2017.

BARTHES, Roland. O rumor da língua. São Paulo: Martins Fontes, 2004.

BAUMAN, Zygmunt. A sociedade individualizada: vidas contadas e histórias vividas. Rio de Janeiro: Zahar, 2008.

BERTALANFFY, Ludwig von. General system theory: foundations, development, aplications. New York: George Braziller, 1969.

BÍBLIA SAGRADA. Edição Ecumênica. Rio de Janeiro: Britannica Publishers, 1977.

BRASIL. Constituição (1988). Constituição da República Federativa do Brasil de 1988. Disponível em: <http://www.planalto.gov.br/ccivil_03/constituicao/constituicao.htm>. Acesso em: 4 ago. 2018.

BRASIL. Decreto $\mathrm{n}^{\circ} 75.699$, de 6 de maio de 1975. Promulga a Convenção de Berna para a Proteção das Obras Literárias e Artísticas, de 9 de setembro de 1886, revista em Paris, a 24 de julho de 1971. Disponível em: <http://www.planalto.gov.br/ccivil_03/decreto/19701979/d75699.htm>. Acesso em: 4 ago. 2018.

BRASIL. Lei $\mathrm{n}^{\circ}$ 9.609, de 19 de fevereiro de 1998. Dispõe sobre a proteção da propriedade intelectual de programa de computador, sua comercialização no País, e dá outras providências. Disponível em: <http://www.planalto.gov.br/ccivil_03/leis/19609.htm>. Acesso em: 4 ago. 2018.

BRASIL. Lei $\mathrm{n}^{\circ}$ 9.610, de 19 de fevereiro de 1998. Altera, atualiza e consolida a legislação sobre direitos autorais e dá outras providências. Disponível em: <http://www.planalto. gov.br/ccivil_03/leis/19610.htm>. Acesso em: 4 ago. 2018.

CAMPBELL, Neil A. et. al. Biologia. 8. ed. Porto Alegre: Artmed, 2010.

CARBONI, Guilherme. Direito autoral e autoria colaborativa na economia da informação em rede. São Paulo: Quartier Latin, 2010.

CARBONI, Guilherme. Função social do direito de autor. Curitiba: Juruá, 2008.

CARBONI, Guilherme. Função social do direito de autor. In: TIMM, Luciano Benetti; MACHADO, Rafael Bicca. Função social do direito. São Paulo: Quartier Latin, 2009.

CASSIRER, Ernst. Linguagem e mito. São Paulo: Perspectiva, 2011.

DESCARTES, René. Discurso do método. São Paulo: Martins Fontes, 1996. 
ECHEVERRÍA, Rafael. Ontología del lenguaje. 6. ed. Chile: J. C. Sáez, 2003.

ELIAS, Norbert. A sociedade dos indivíduos. Rio de Janeiro: Zahar, 1994.

FOUCAULT, Michel. O que é o autor? In: FOUCAULT, Michel. Estética: literatura e pintura, música e cinema. Rio de Janeiro: Forense Universitária, 2001. [Ditos e escritos: vol. III],

FREIRE, Paulo. Educação e mudança. 15. ed. São Paulo: Paz e Terra, 1989.

GALIMBERTI, Umberto. Psiche e techne: o homem na idade da técnica. São Paulo: Paulus, 2006.

KROKOSCZ, Marcelo. Outras palavras sobre autoria e plágio. São Paulo: Atlas, 2015.

LIPOVETSKY, Gilles. A sociedade pós-moralista: o crepúsculo do dever e a ética indolor dos novos tempos democráticos. Barueri: Manole, 2005.

MORIN, Edgar. Introdução ao pensamento complexo. 4. ed. Porto Alegre: Sulina, 2011.

MORIN, Edgard; KERN, Anne Brigitte. Terra-pátria. Porto Alegre: Sulina, 1995.

MOURÃO, José Augusto. Para uma poética do hipertexto. Lisboa: Edições Universitárias Lusófonas, 2001.

ONU. Organização das Nações Unidas. Declaração Universal dos Direitos Humanos. Resolução 217 A (III) da Assembleia Geral. Disponível em: <http://www.un.org/ ga/search/view_doc.asp?symbol=A/RES/217(III)\&Lang=E>. Acesso em: 4 ago. 2018.

PEREIRA, Otaviano. O que é a moral. São Paulo: Brasiliense, 1991.

RIBEIRO, Eduardo Ely Mendes. Individualismo e verdade em Descartes: o processo de estruturação do sujeito moderno. Porto Alegre: EDIPUCRS, 1995.

RUGIU, Antonio Santoni. Nostalgia do mestre artesão. Campinas: Autores Associados, 1998.

SARTRE, Jean Paul; PESSANHA, Jose Americo Motta. O existencialismo é um humanismo: a imaginação; questão de método. 3. ed. São Paulo: Nova Cultural, 1987.

TODOROV, Tzvetan. O espírito das luzes. São Paulo: Barcarolla, 2008.

TOURAINE, Alain. Crítica da modernidade. 5. ed. Petrópolis: Vozes, 1998. 